\title{
Laboratory Education in New Zealand
}

\author{
Thomas Borrmann \\ Victoria University of Wellington, Wellington, NEW ZEALAND
}

Received 3 April 2008; accepted 11 July 2008

\begin{abstract}
Laboratory work is one of the main forms of teaching used in chemistry, physics, biology and medicine. For many years researchers and teachers have argued in favor or against this form of education. Student opinion could be a valuable tool for teachers to demonstrate the validity of such expensive and work intensive forms of education as laboratory work. However, due to concerns regarding overly positive replies and a strong personal bias in opinions regarding various courses, teachers and technicians, student opinion has largely been discounted so far. A set of markers based on the strategic aims of Victoria University of Wellington, New Zealand, have been selected and used to collect student opinion. The markers appear to be independent and present a more objective view of the value of student opinion regarding laboratory education. In contrast, direct questions showed exactly the positive bias criticized by researchers and academics. The markers based on strategic aims revealed that laboratories are valued but that certain areas of this form of education require improvement. The trends collected by use of the markers were line with replies to free-form questions and could therefore present a valid option for researchers to evaluate the effectiveness of various forms of education based on the opinions of the people most concerned, the students.
\end{abstract}

Laboratory education; Strategic Aims, Students' Opinions, Survey Validity

\section{INTRODUCTION}

Laboratory work is one of the main forms of teaching used in chemistry, physics, biology and medicine. Studies carried out in the seventies and eighties showed that students did not enjoy laboratory work (Beard and Hartley, 1984; Bliss and Ogborn, 1977, Boud, Dunn, \& Hegarty, 1986; Hegarty, 1984), which came as no surprise looking at the effort (workload, commitment) and risks (chemical burns, poisoning) associated with it (chemical burns, poisoning etc.). Since then safety technology has been improved to a point where laboratory work is safe and in principle, enjoyable. But the technology improving laboratory conditions brought a significant increase in costs and

Correspondence to: Thomas Borrmann, School of Chemical and Physical Sciences and the MacDiarmid Institute for Advanced Materials and Nanotechnology, Laby Building, Room 402, Victoria University of Wellington, P.O.Box 600, 6140 Wellington, New Zealand

E-mail: thomas.bormann@vuw.ac.nz. effort to equip and maintain practical work areas, raising financial questions regarding their necessity and viability. New Zealand's tertiary education budget is above average for Organization for Economic Cooperation and Development (OECD) countries with $1.7 \%$ compared to $1.4 \%$ of the Gross Domestic Product (GDP) (examples: Ireland 1.3\%, Finland and Sweden $1.7 \%$ and Australia 1.5\%) to address continuing skills shortages (LaRocque, 2007). The GDP of New Zealand is approximately three quarters of that of other OECD countries (for example Finland and Ireland) meaning that the actual amount of funding available for tertiary education is comparatively low. Furthermore, the market-driven nature of New Zealand universities and educational institutions places limitations on the willingness of financers and managers to approve comparatively costly forms of education (Kelsey, 1998).

Doubts about education in laboratory environments are not limited to managers and financiers; teachers, lecturers and students have discovered new technologies, which can be applied in teaching at a fraction of the costs and effort of laboratory education (Bodner, 2001; Grosso, 1995; Walton, 2002; Willet, 
2006). The discussion about laboratories and other educational techniques is very opinionated, with many scientists arguing heatedly either in favour (Blosser, 1990; Bond-Robinson, 2005; DeMeo, 2001; DiBase and Wagner, 2001; Hofstein, 2004; Johnstone and AlShuaili, 2001; Kampourakis and Tsaparlis, 2003; Lloyd, 1992; Stanholtzner, 2002; Stanholtzner, 2003) or against (Balla, 1990; Hawkes, 2004) laboratory education. Recently, the online journal Chemistry Education Research and Practice (2007) dedicated a special issue to articles about "Experiments and the Laboratory in Chemistry Education". Several articles in this edition of the journal discuss the history, development and current standard in laboratory education.

One question is often ignored in this context: What do students think about laboratory education? In 2006 John Steven Polles wrote a PhD thesis investigating the student perspective on chemistry teaching laboratories. Polles (2006) found that students' experiences were strongly dependent on their learning environment and the stance of their teachers, lecturers, demonstrators and technicians. This dependence raises questions regarding the validity of assessing student opinion. Many academics feel that students tend to give overly positive replies that do not reflect their true opinions regarding different forms of education, if asked directly. However, if independent and indirect instead of direct questions are used, where, for example, students comment on the realization of certain aims and goals instead of commenting on the matter in question directly, a more objective and useful opinion poll might be collected. A comparison of the direct and indirect method of questioning, for example in a survey, should show a difference in the distribution of opinions depending on the method of questioning. It is postulated that asking students about the realization of aims and goals in a course should yield a wider spread of replies overall and clear differences in the opinions regarding various goals and markers. This is in contrast to direct questioning, which yields positive but dubious results as expressed in a lack of spread between replies to different questions. Therefore, the validity of an indirect approach for collecting students' opinions can be shown by an investigation of the statistical distribution of replies. Should the distribution yield a believable spread and prove questions to be independent, students' opinions might be considered more valuable and useful in deciding on the quality and usefulness of different forms of chemistry education.

\section{Case Study - An Investigation of Students' Opinions Regarding Chemistry Laboratory Education}

As a case study an investigation of students' opinions regarding chemistry laboratory education was chosen.
The reasons for this choice were the familiarity of the investigator with the subject area and the clarity of the aims and goals formulated. Based on statements from the strategic plan of Victoria University of Wellington, New Zealand, and conversations with the Dean of Science, with lecturers in chemistry and the Head of the School of Chemical and Physical Sciences a list of the seven most important joint strategic goals for the University and the School was collated. The goals are directly linked to generic, course-independent attributes, which a chemistry student at Victoria University should have or attain during study. The list was limited to seven items based on the weighting attributed to the individual goals in the discussions. Between the selected seven items and other items not included in this study a perceivable step in weighting was noticed. According to University and School guidelines the goals assessed in this study should be realized in the teaching curriculum, for examples in the university calendar, course outlines and reports.

The seven attributes thought to be the seven most important (in no particular order) are:
i. Confidence
ii. Interest
iii. Linking theory with observation
iv. Critical thinking
v. Scientific methods like analysis, observation and the deduction of results based on observations
vi. Leadership skills
vii. Practical skills

A questionnaire was formulated and distributed in chemistry lectures and laboratories of all levels in the last week of the second trimester in 2006. Ethical standards were strictly obeyed in the collection and handling of the questionnaire, a copy of which is available as appendix. Early in the planning of the presented study the need for strict limits was noticed. These limits were set in order to minimize disruptions to the students' curriculum and were realized by focusing on seven strategic goals perceived as most important by the University and School (listed above). Furthermore, the study was limited in terms of the data collection method applied - meaning that the only method of collecting data used in this study was a questionnaire. A small follow-up study was carried out mid 2007 to elucidate the effect of level on the results obtained. Further follow-up studies should investigate the same set of goals using other techniques, for example interviews of focus groups, to ensure the validity of the results presented here.

The questionnaire was structured into four blocks, the first being used to accumulate demographic information about the students participating (enrolment in lectures, enrolment in laboratory courses, number of laboratory courses participated in, involvement in research projects, gender, origin, and status - 1st Year, 
Table 1. Return rate

\begin{tabular}{lllll}
\hline Level & $\begin{array}{l}\text { Students } \\
\text { Enrolled, No. }\end{array}$ & $\begin{array}{l}\text { Questionnaires } \\
\text { Distributed, No. } \\
\text { (Percentage) }\end{array}$ & $\begin{array}{l}\text { Questionnaires } \\
\text { Returned, No. } \\
\text { Percentage) }\end{array}$ & $\begin{array}{l}\text { Return Rate - Returned } \\
\text { Questionnaires/Enrolled } \\
\text { Students (Percentage) }\end{array}$ \\
\hline 100 & 189 & $147(77.8 \%)$ & $107(72.8 \%)$ & $0.566(56.6 \%)$ \\
200 & 72 & $67(93.1 \%)$ & $62(92.5 \%)$ & $0.861(86.1 \%)$ \\
300 & 24 & $22(91.7 \%)$ & $18(81.8 \%)$ & $0.750(75.0 \%)$ \\
All & 285 & $236(82.8 \%)$ & $187(79.2 \%)$ & $0.656(65.6 \%)$ \\
\hline
\end{tabular}

Table 2. Statistics from direct questions asked regarding the value of laboratory education

\begin{tabular}{lllll}
\hline & $\begin{array}{l}\text { General } \\
\text { Understanding }\end{array}$ & $\begin{array}{l}\text { Understanding Key } \\
\text { Concepts }\end{array}$ & Time and Effort & $\begin{array}{l}\text { Achievements } \\
\text { and Progress }\end{array}$ \\
\hline Median & 3.7123 & 3.5189 & 3.4764 & 3.4811 \\
Mean & 4.0000 & 3.5000 & 3.2500 & 4.0000 \\
Std Dev & 1.0023 & 0.8421 & 0.9471 & 0.9282 \\
Std Err & 0.0973 & 0.0818 & 0.0920 & 0.0902 \\
$95 \%$ Conf & 0.1930 & 0.1622 & 0.1824 & 0.1788 \\
$90 \%$ Conf & 0.2554 & 0.2146 & 0.2414 & 0.2365 \\
Size & 106 & 106 & 106 & 106 \\
Total & 393.5 & 373 & 368.5 & 369 \\
Min & 1.0 & 1.0 & 1.0 & 1.0 \\
Max & 5.0 & 5.0 & 5.0 & 5.0 \\
Min Pos & 1.0 & 1.0 & 1.0 & 1.0 \\
\hline
\end{tabular}

2nd Year etc.). The second block contained four direct questions regarding the general value of laboratory education, (1) evaluating how laboratories contribute to the general understanding of chemistry, (2) the understanding of key concepts, (3) the value of practical education in respect to time and effort spent and (4) the achievements and progress in chemistry. The third block (the indirect part) asked how far the strategic aims listed above are realized in Victoria University chemistry laboratory courses. The last block contained four freeform questions, asking for feedback on the positive and negative aspects of laboratory education, suggestions for improvements and general comments.

Answers to the questions were categorical to avoid confusion, with five categories given - the positive always being on the left and the negative always being on the right hand side (see appendix). Students were told that they could choose two categories to express that their answer lies between the categories given. This means that a total of nine categorical answers were possible for each question. For the evaluation of the student's answers, the five main categories and four intermediates were translated into a 9-point scale of numbers, ' 5 ' standing for most positive and ' 1 ' for most negative possible. The step width was 0.5 (meaning answers could have the following values: 5.0, 4.5, 4.0, $3.5,3.0,2.5,2.0,1.5,1.0)$. After compilation of statistical data (calculation of means, errors, chi-tests etc.) and construction of box plots the numbers were transformed back into categories for interpretation of the results calculated.

\section{Return Rate}

One of the issues facing any study is that of return rate: Is the sample group participating in a study representative of the student population? In this study it was decided to choose all enrolled chemistry students as population. As no sampling was undertaken the study should be representative of the opinions of all chemistry students at Victoria University. It was further decided to carry out a survey close to the end of a trimester. This choice of time means that students are pre-occupied with exams, assignments and presentations and attendance levels and response rates to questionnaires can be low. This is offset by the higher level of experience the students have accumulated. As experience of laboratory teaching is important for the purposes of this study, a lower response rate was accepted as a risk. As expected attendance levels had dropped (Table 1). However, even an attendance of $77.8 \%$, as on the 100 -level (1st year students), is respectable. Therefore, a return rate of $72.8 \%$ means that $56.6 \%$ of all 100-level students enrolled in chemistry participated in this study, which means that it can be considered representative. The values for 200level (2nd year students) and 300-level (3rd year students) are even better, $86.1 \%$ and $75.0 \%$ respectively. This means that a total of $65.6 \%$ of all undergraduate 
Table 3a. Realization of strategic aims in laboratory education; Part 1

\begin{tabular}{llll}
\hline & Confidence & Interest & Linking Theory with Observation \\
\hline Median & 3.4764 & 3.4387 & 3.5896 \\
Mean & 4.0000 & 4.0000 & 4.0000 \\
Std Dev & 0.9370 & 1.0904 & 0.9631 \\
Std Err & 0.0910 & 0.1059 & 0.0935 \\
$95 \%$ Conf & 0.1805 & 0.2100 & 0.1855 \\
$90 \%$ Conf & 0.2388 & 0.2779 & 0.2454 \\
Size & 106 & 106 & 106 \\
Total & 368.5 & 364.5 & 380.5 \\
Min & 1.0 & 1.0 & 1.0 \\
Max & 5.0 & 5.0 & 5.0 \\
Min Pos & 1.0 & 1.0 & 1.0 \\
\hline
\end{tabular}

Table 3b. Realization of strategic aims in laboratory education; Part 2

\begin{tabular}{lllll}
\hline & Critical Thinking & Scientific Method & Leadership & Practical Skills \\
\hline Median & 3.1132 & 3.8113 & 2.2311 & 3.9292 \\
Mean & 3.0000 & 4.0000 & 2.0000 & 4.0000 \\
Std Dev & 0.8654 & 0.8178 & 0.9836 & 0.8603 \\
Std Err & 0.0841 & 0.0794 & 0.0955 & 0.0836 \\
$95 \%$ Conf & 0.1667 & 0.1575 & 0.1894 & 0.1657 \\
$90 \%$ Conf & 0.2205 & 0.2084 & 0.2507 & 0.2192 \\
Size & 106 & 106 & 106 & 106 \\
Total & 330 & 404 & 236.5 & 416.5 \\
Min & 1.0 & 1.0 & 1.0 & 1.0 \\
Max & 5.0 & 5.0 & 5.0 & 5.0 \\
Min Pos & 1.0 & 1.0 & 1.0 & 1.0 \\
\hline
\end{tabular}

Table 4. Comparison of average medians, spread of medians and maximum standard error for years 1-3

\begin{tabular}{lllllll}
\hline Year & $1^{\text {st }}$ & & 2 & & \multicolumn{2}{l}{$3^{\text {rd }}$} \\
\hline Questions & Direct & Indirect & Direct & Indirect & Direct & Indirect \\
Average Median & 3.55 & 3.36 & 3.74 & 3.61 & 4.18 & 3.95 \\
Spread of Median & \pm 0.09 & \pm 0.52 & \pm 0.12 & \pm 0.51 & \pm 0.23 & \pm 0.49 \\
Max Std Err & 0.10 & 0.11 & 0.12 & 0.13 & 0.22 & 0.25 \\
\hline
\end{tabular}

students enrolled in chemistry at Victoria University participated in this study. It is possible but not expected that the opinions of these students differ significantly from the opinions of all chemistry students.

\section{Comparison of Results - Direct Questions versus Indirect Indicators (Strategic Aims)}

Looking at the replies for the first year students, the distribution of medians for the direct questions regarding the value of laboratory education is $3.55 \pm$ 0.09. This spread of results is well within the standard error of each of the four individual results (Table 2). The consistency of replies raises serious doubts regarding their value. It is quite possible that the positive aspect of the replies is overstated and approval for laboratory education solely based on these results would be over-estimated. A graphical interpretation of the spread of results between the different questions can be found in Figure 1. The size of the spheres is equivalent to the number of replies. Table $3 \mathrm{a}$ and $\mathrm{b}$ show that the distribution of medians for the indirect questions regarding the realization of strategic aims in laboratory education is far less uniform. The average of the medians shows a far larger spread with a value of 3.4 \pm 0.5 . The standard errors for the individual strategic aims are of the same order and magnitude as those for the direct questions. This indicates that the results in themselves for the indirect questions are as consistent as the direct questions, but the spread of the means is five times as large compared to the standard errors, indicating that the variables assessed are independent 


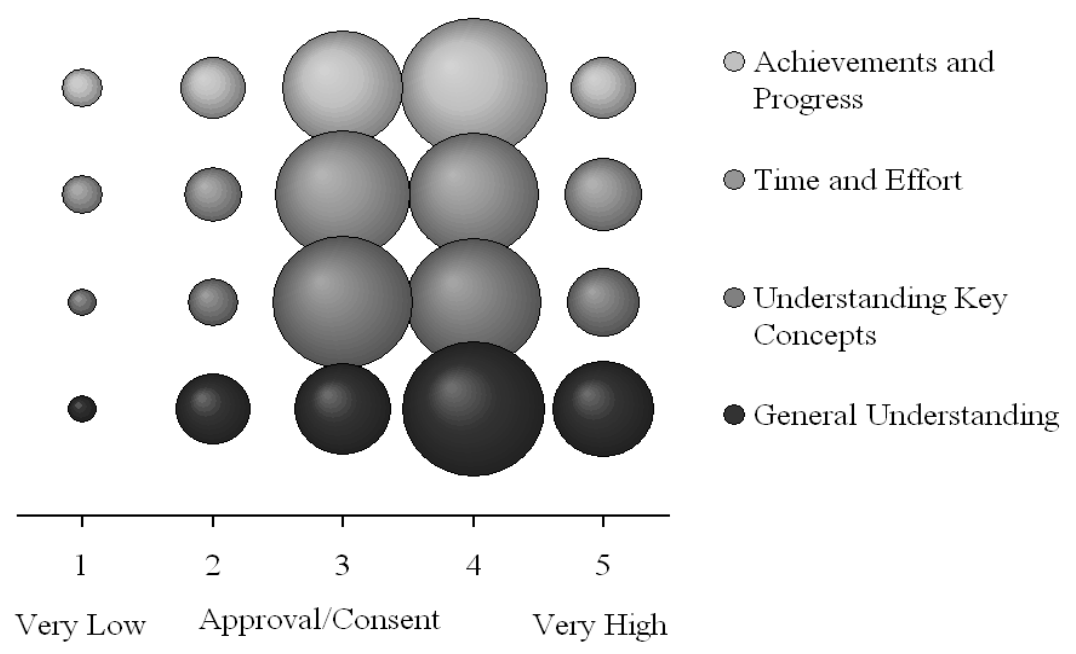

Figure 1. A bubble plot showing the distribution of answers to the direct questions regarding the value of laboratory education

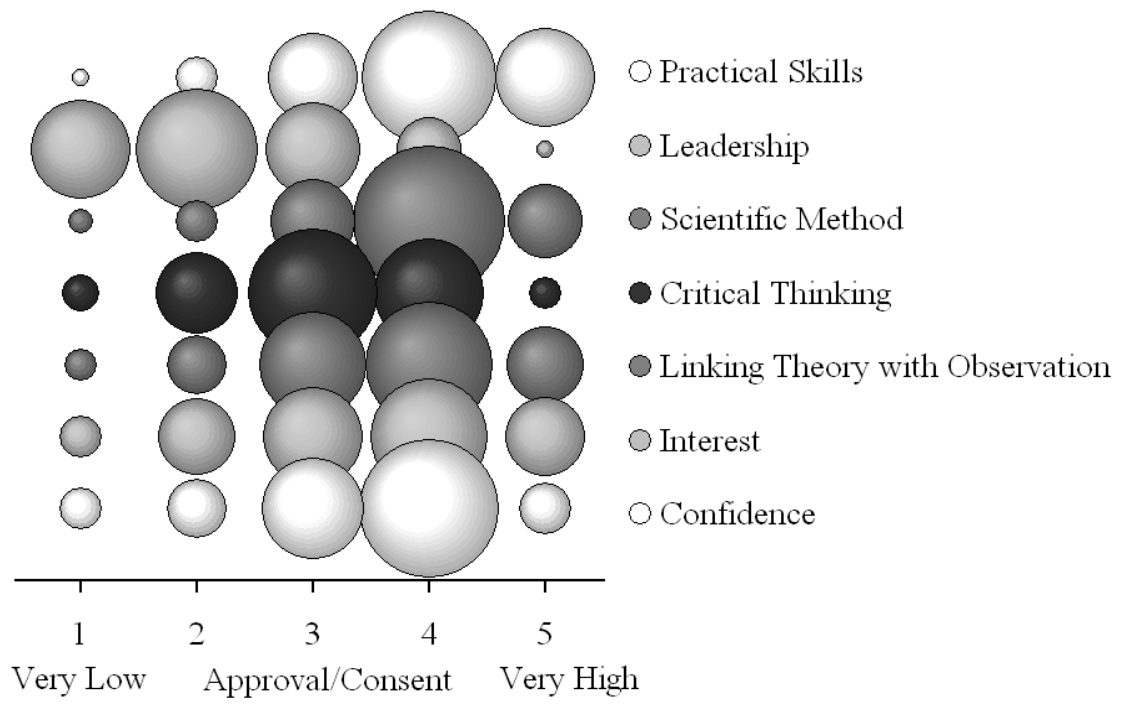

Figure 2. A bubble plot showing the distribution of answers to the indirect questions regarding the realization of strategic aims in laboratory education

and probably closer related to the real opinions of the students. The question regarding leadership even yielded a response slightly below medium. A graphical representation of the spread of results between the different strategic aims is shown in Figure 2. The size of the spheres is equivalent to the number of replies.

Results for years 2 and 3 show similar statistics but as the sample size decreases the standard errors increase, while the spread of results remains similar. A comparison distinguishing between direct and indirect questions of the standard errors (maxima only), average medians and their spread for the years 1 to 3 is presented in Table 4 . In principle the postulation appears to be true that using indirect questions gives a wider spread of results than the more direct approach. It appears that the results from the direct questions indeed over-estimated the positive nature of students' opinions and were of limited usefulness to assess the value of laboratory education. In return this indicates that the indirect method has some degree of validity and that the strategic aims chosen, as indicators are useful assessment tools.

Interpretation of Results from the Direct Questions Regarding the Value of Laboratory Education

In general the attitude towards laboratory education is positive. The medians for all answers are in the range between average and positive (Table 2). The interquartile range as calculated from the probability density function is nearly always within one main 
category; the only exception is the question regarding the contribution of laboratories to the general understanding of chemistry. All observations are within two to three main categories, meaning that the opinions are very consistent for all students participating. While answers were received in all five main and four intermediate categories, the most negative opinions were only present as outliers, meaning that answers in them are located more than one main and one intermediate category outside of the interquartile range. Less than $1 \%$ of all students have a negative or very negative opinion about laboratory education.

This is illustrated in Figure 3, a box plot created according to guidelines by Tukey and Iglewicz (1989). In light of the study carried out by Polles (2006), this could mean that the learning environment in the laboratories was supportive and positive, credit to the chemistry staff of Victoria University. However, as the statistical analysis of the results indicates that results might be overly positive, care must be taken in the interpretation of these findings. As before the plot in Figure 3 was constructed from the surveys collected from $1^{\text {st }}$ year students as the larger numbers gave an adequate frequency of responses (Figure 4). While the margin of error increased, the distributions for $2^{\text {nd }}$ year and $3^{\text {rd }}$ year students compared to $1^{\text {st }}$ year and for students from all years, the histograms appear to follow approximately the same shape, which indicates that results are valid and can be used for modelling replies and constructing box plots.

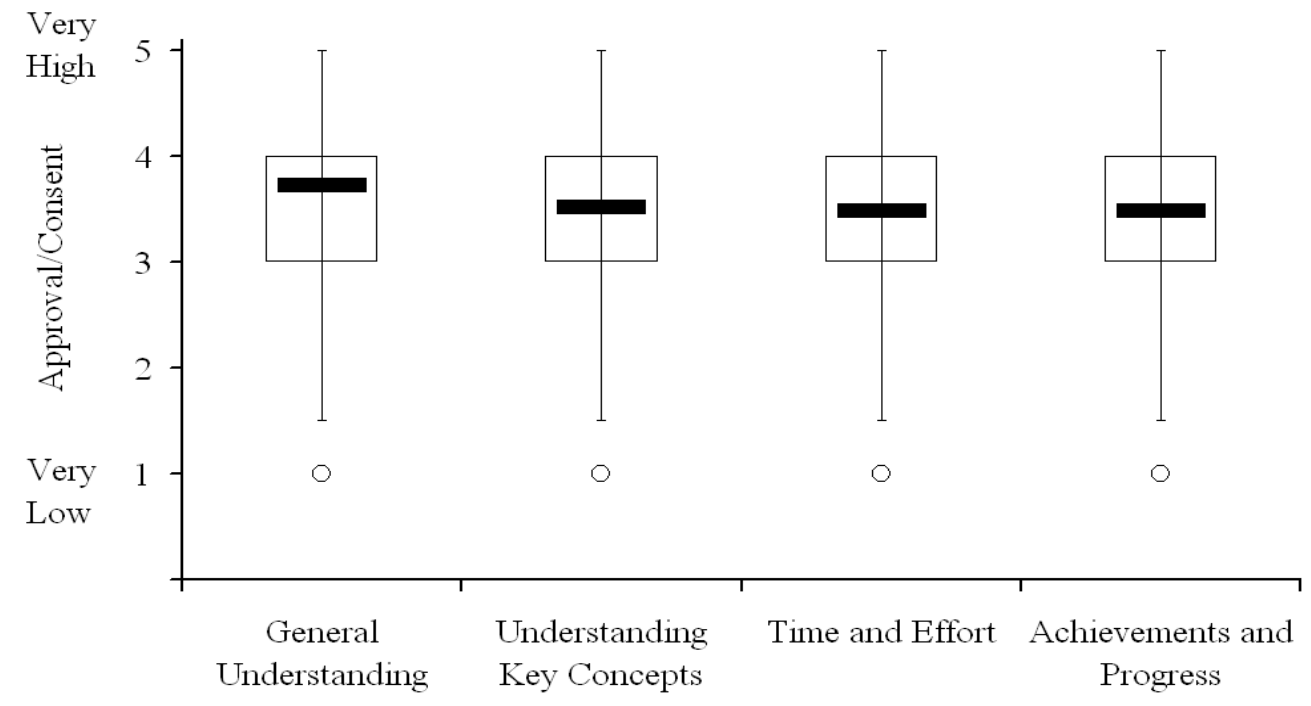

Figure 3. Box plot showing the spread of opinions of 1st year students regarding laboratory education assessed by direct questions

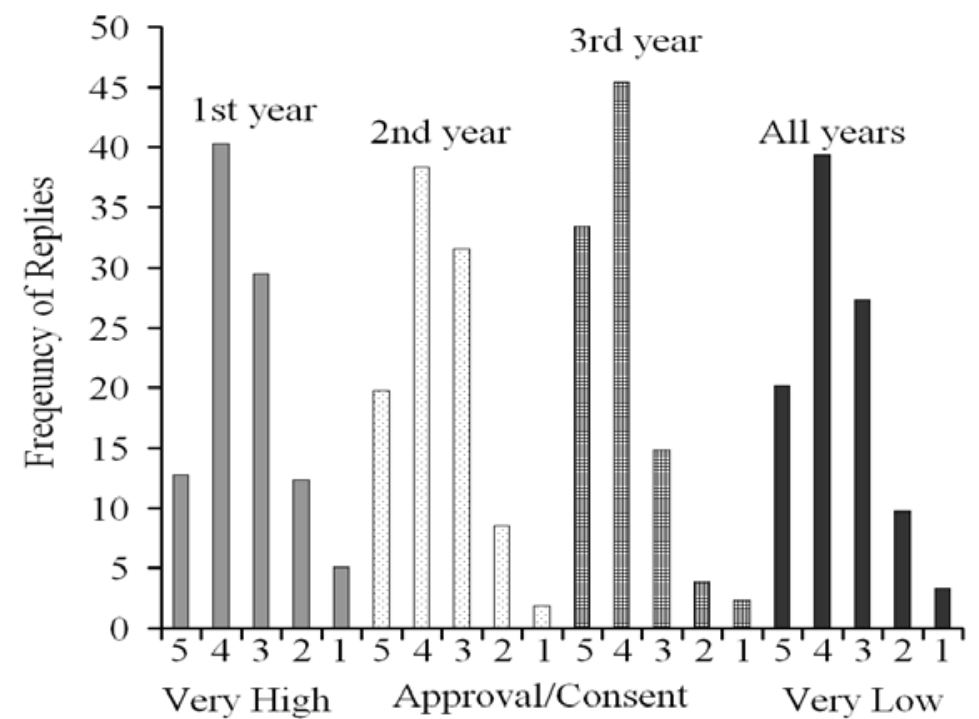

Figure 4. Histogram showing the frequency of replies in each approval category: $1=$ very low, $2=$ low, $3=$ average, $4=$ high, $5=$ very high 


\section{Opinions Regarding the Realization of Strategic} Aim

Results in terms of the strategic aims are more diverse (Figure 5). Aims in regards to confidence, interest, linking theory with observation, and scientific method have been achieved well, with replies being between neutral and positive. Critical thinking is not realized as well, with opinions tending more towards a neutral position. It is likely that due to a relatively narrow knowledge, undergraduate students have not yet had sufficient opportunity to train themselves in the evaluation and discussion of concepts. Pending findings among the postgraduate students, this might be an issue that should be discussed amongst and remedied by the academic staff and students. Leadership was the only strategic aim not fully realized in chemistry laboratories. The undergraduate laboratories leave little room for the students to take leadership roles. Owing to safety considerations, instructions, guidelines and requirements are precise and strict, especially for 100-level students, allowing little room for taking leading roles. Only on 300-level do students start to embark on self-guided independent research. Whether this independence is reflected in their tendency towards this strategic aim will be discussed below. One other strategic aim is prominent - practical skills, which due to the nature of laboratory courses is not surprising. Opinions regarding the acquisition of these skills are positive to very positive with the median lying above the positive category.

Several researchers have investigated the relation between laboratory work, lectures and other teaching techniques (Bodner, 2001; Grosso, 1995; Walton, 2002; Willet, 2006). DiBase (2002) and Polles (2006) both came to the conclusion that a good alignment between

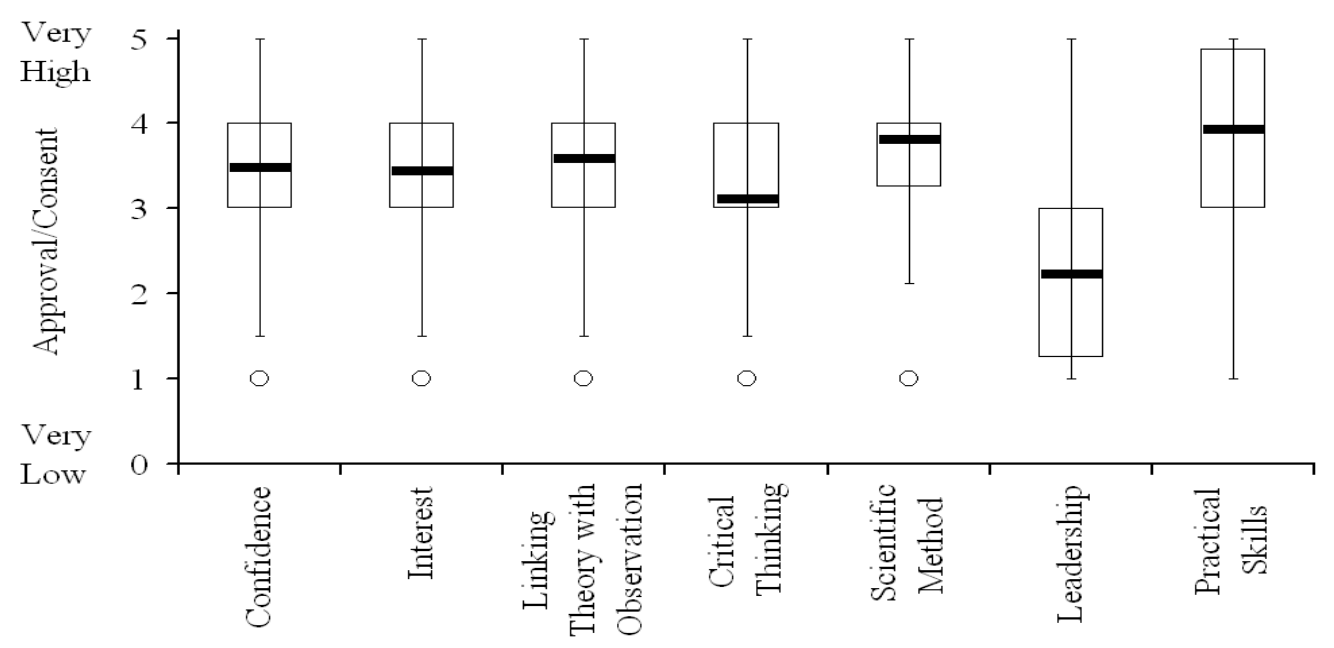

Figure 5. Box plot showing the spread of opinions of 1st year students regarding laboratory education assessed by indirect questions. Students were asked to judge the degree at which strategic aims were realised in laboratory education

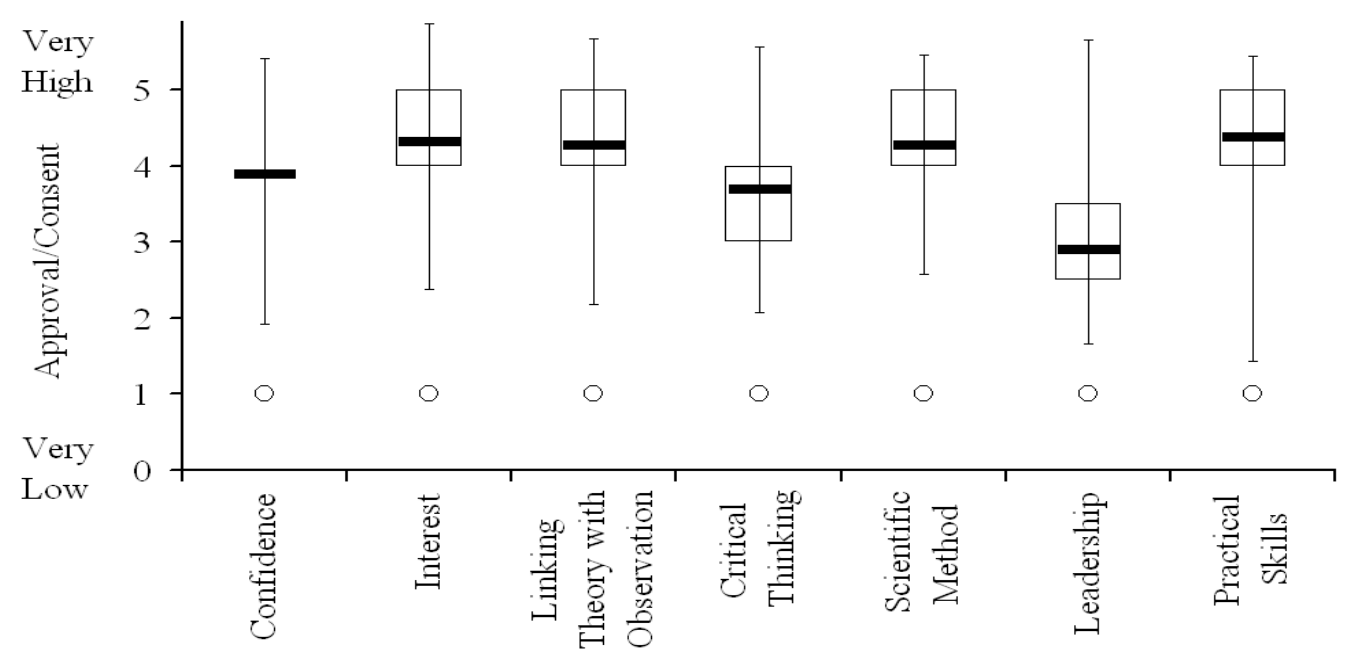

Figure 6. Box plot showing the spread of opinions of $3^{\text {rd }}$ year students regarding laboratory education assessed by indirect questions 
the different forms of teaching needs to be achieved for maximum effectiveness. DiBase (2002) and Deters (2005) have both suggested strategies for how this may be achieved. The effectiveness of the link between the different teaching techniques, lectures and laboratories, at Victoria University was documented in the corresponding question (see Figure 5. Linking theory and observation) and in the free-form part of the questionnaires, where $31.3 \%$ of the students stated that laboratories helped them understand concepts and how they relate to observations and findings, something which is difficult to achieve, if the students are only presented with data and do not carry out the experiments. Further positive points mentioned by approximately a quarter of the students were visual learning $(22.9 \%)$ and the acquisition of practical skills $(27.7 \%)$. Negative remarks - only comments about the high workload and time required were stated by a significant amount of students (28.2\%). Only $33.2 \%$ of all participating students used the free-form questions.

The raw data has been submitted to Chi-square tests to see if group (other than level) specific trends would be noticeable by correlation of the replies to the questions with demographic data also collected in the questionnaire. The result was overwhelmingly negative, with the error in the Chi-square test being unacceptably high $(22 \%)$, which means that no statistical significance for differences between any of the demographical groups has been observed.

While the spread of results includes negative as well as positive opinions, the overall trend is quite positive, with students' opinions being quite favourable towards laboratory education.

\section{The Development of Opinion through the Levels}

Student opinions, regarding the alignment of laboratory education and strategic aims, improve as students advance through the levels. While there is a noticeable improvement in opinion between 100-level and 200-level, the opinions expressed by 300-level students are very positive (Figure 6). Victoria University has a policy of research-led teaching in line with good teaching practice as formulated by Vallarino, Polo, \& Esperdy (2001). At 300-level the students become involved in independent three-week research projects. Nearly all opinions are in the range between positive and very positive. Only the opinions regarding the realization of critical thinking and leadership in laboratory education are still lower than the rest, but even they are significantly improved, with critical thinking tending towards a positive rating and the opinions regarding leadership being expressed relatively evenly around the neutral mark.
Seeing the improvement in opinions as the students advance through the levels, one question remains: Did student opinion improve or did the students with negative and neutral opinions move to other subject areas? This question was answered in a short follow-up study that showed that over $95 \%$ of the students' opinions improved as they progressed through the levels. The follow-up study included students moving to other subject areas; of the seventy-two 200-level students surveyed initially $52(72.2 \%)$ were included and replied to the follow-up study. Of these 52 students 38 were still pursuing a chemistry degree at Victoria University. The students commented that this improvement in opinion is due to better linkages between lectures and laboratories at 300-level than at the lower levels.

\section{CONCLUSION}

The presented study yielded two results. First, responses from asking students directly to assess the value of laboratory education were compared to questions where students assessed the realisation of strategic aims in Victoria University of Wellington laboratory courses. It was shown that the direct questions over-estimate the approval of students for the form of education they are undergoing. The strategic aims appeared to act as independent indicators giving a far more realistic picture of student opinion. The second result from this study is the finding that even the indirect questions yielded a positive result. Students appear to value laboratory education highly and as they progress through the levels and the linkages between lecture and laboratory materials increases the appreciation of students for laboratory education grows as well. Several strategic aims, especially those regarding confidence, interest, linking theory with observation, scientific method and practical skills have been achieved quite well, with replies ranging between neutral and positive. Critical thinking and leadership are not realised well and laboratory personnel and academics should consider how to improve laboratory education in this regard. Lectures and other forms of teaching and learning usually achieve better results in regards to critical thinking, but fall short in terms of inspiring confidence, interest, and linking theory with observation. In light of the achievements of laboratory education, and the way it compliments other forms of education, it remains important to keep it despite the (sometimes) high costs involved. Student opinion certainly appears to places a value on it, and teachers and academics are wise to consider the opinions of their students. 


\section{REFERENCES}

Balla, J. I. (1990). Insights into some aspects of clinical education - I. Clinical practice. Postgraduate Medical Journal, 66, 212-17.

Beard, R. M. and Hartley, J. (1984). Teaching and Learning in Higher Education. London: Harper \& Row.

Bliss, J. and Ogborn, J. (1977). Students' reactions to undergraduate science. London: Heinemann.

Blosser, P. E. (1990). The Science Process Skills. Research Matters to the Science Teacher, No. 9004, 1 - 4.

Bodner, G. M. (2001). Why lecture demonstrations are 'exothermic' for both students and their instructors. University Chemistry Education, 5, 31 - 35.

Bond-Robinson, J. (2005). Identifying pedagogical content knowledge (PCK) in the chemistry laboratory. Chemistry Education Research and Practice, 6(2), 83 - 103.

Boud D., Dunn, J. \& Hegarty, H. E. (1986). Teaching in Laboratories. Guildford: SRHE \& NFER-NELSON.

Chemistry Education Research and Practice. (2007). Special Issue on Experiments and the Laboratory in Chemistry Education. Chemistry Education Research and Practice, 8(2), http:/ /www.rsc.org/Education/CERP/

DeMeo, S. (2001). Teaching Chemical Technique. Journal of Chemical Education, 78(3), 373-379.

Deters, K. M. (2005). Student Opinions Regarding InquiryBased Labs. Journal of Chemical Education, 82(8), 11781180.

DiBase, W. J. and Wagner, E. P. (2002). Aligning General Chemistry Laboratory with Lecture at a Large University. School Science and Mathematics, 102(4), 158171.

DiBase, W. J. and Wagner, E. P. (2001). Reconceptualizing a general chemistry curriculum using a standards-based approach to instruction. Association for the Education of Teachers in Science (AETS) Annual International Meeting, Costa Mesa, Ca. Jan. 17-21. http://www.ed.psu.edu/CI/Journals/2001aets/s4_08_ dibiase_wagner.rtf

Grosso, M. R. (1994). The comparison of computer simulation and traditional laboratory exercises in a college freshman chemistry course. State University of New York at Buffalo, USA: $\mathrm{PhD}$ thesis.

Hawkes, S. J. (2004). Chemistry Is Not a Laboratory Science. Journal of Chemical Education, 81(9), 1257.

Hegarty, E. H. (1984). The role of laboratory work in science courses: Implications for college and high school levels. In Rowe, M. B. (Ed.), Education in the 80s: Science. Washington DC: National Education Association.

Hofstein, A. (2004). The laboratory in chemistry education: thirty years of experience with developments, implementation, and research. Chemistry Education Research and Practice, 5(3), 247 - 264.

Johnstone, A. H. and Al-Shuaili, A. (2001). Learning in the laboratory; some thoughts from the literature. University Chemistry Education, 5, 42-51.

Kampourakis, C. and Tsaparlis, G., (2003). A study of the effect of a practical activity on problem solving in chemistry. Chemistry Education Research and Practice, 4(4), 319-333.
Kelsey, J. (1998). Privatizing the Universities. Transformative Visions of Legal Education. Journal of Law and Society, 25(1), 51-70.

LaRocque, N. (2007). Skill development and skill shortages in New Zealand. Education Forum. 1. Human capital - New Zealand. 2. Labour supply -

New Zealand. I. Education Forum (N.Z.) II. 331.1140993-dc 22, ISBN 978-0-9582725-3-7; www.educationforum. org.nz.

Lloyd, B. H. (1992). The 20th Century General Chemistry Laboratory. Journal of Chemical Education, 69(11), 866869.

Polles, J. S. (2006). The chemistry teaching laboratory: The student perspective. Purdue University, Indiana, USA PhD-thesis.

Stanholtzner, S. (2003). A comparison of grades for students taking a traditional lecture course without the laboratory. In O'Donnell, M. A. (Ed.), Tested studies for laboratory teaching, Volume 24, Proceedings of the 24th Workshop/Conference of the Association for Biology Laboratory Education (ABLE), 317 - 320.

Stanholtzner, S. (2002). What is the value of the lab? Labstracts, $2-7$.

Tukey, J. W. and Iglewicz, B. (1989). Some Implementations of the Boxplot. The American Statistician, 43(1), 50-54.

Walton, P. H. (2002). On the use of chemical demonstrations in lectures. University Chemistry Education, 6, 22 - 27.

Willett, G. M. (2006). A comparative evaluation of teaching methods in an introductory neuroscience course for physical therapy students. The Graduate College in the University of Nebraska, USA: PhD-thesis.

Vallarino, L. M., Polo, D. L. \& Esperdy, K. (2001). Development of a Research-Oriented Inorganic Chemistry Laboratory Course. Journal of Chemical Education, 78(2), 228-231. 